\title{
EMISSÃO DE METANO NA RECRIA E TERMINAÇÃO DE BOVINOS SOB DIFERENTES NÍVEIS DE TECNOLOGIA
}

\author{
Tatiane Aparecida Lazari* \\ Jucilene Cavali** \\ Marlos Oliveira Porto*** \\ Elvino Ferreira**** \\ Luciane Cunha Codognoto*****
}

RESUMO: Avaliou-se o desempenho produtivo e a produção de metano em dois sistemas de recria e terminação de bovinos de corte localizados no Estado de Rondônia. O estudo foi desenvolvido em delineamento inteiramente casualizado, com dois tratamentos, sendo utilizados 128 novilhos não castrados, com peso médio inicial de 281,906 $\pm 1,69 \mathrm{~kg}$. Os sistemas produtivos foram classificados pelo nível de tecnologia aplicado, sendo a recria a pasto com suplementação e terminação em confinamento (PSC), considerado o sistema produtivo de uso de alta tecnologia e o sistema com recria e terminação a pasto com suplementação (PS), classificado de nível de média tecnologia. Constatou-se que o sistema PS apresentou maior pressão de pastejo na recria, menor disponibilidade de MS (t/ha) e maior taxa de lotação. No sistema mais tecnificado o tempo de recria foi reduzido em 61 dias, com liberação de 41,42\% menos $\mathrm{CH}_{4}$ por quilo de ganho corporal. E o ciclo de terminação foi concluído 94 dias antes no sistema PSC em relação ao do sistema PS, com 57,20\% menos emissão de $\mathrm{CH}_{4}$ por quilo de ganho corporal, comparativamente entre os sistemas estudados. Desta forma, pode-se concluir que o nível de tecnologia aplicada à produção animal influencia no desempenho animal, o que na avaliação de $\mathrm{CH}_{4}$ por ganho de peso produzido representa menor impacto ao meio ambiente por emissão de gás, há redução no ciclo de produção animal e o retorno financeiro é mais rápido.

\footnotetext{
*Engenheira de Produção, mestre em Ciências Ambientais. Doutoranda no Programa de Pós-Graduação em Administração pela Faculdade de Ciências Econômicas da Universidade Nacional de Missiones (UNAM), Argentina. Docente/pesquisadora no curso de Engenharia de Produção da Universidade Federal de Rondônia (UNIR), campus de Cacoal (RO), Brasil. E-mail: tatiane.lazari@unir.br

${ }^{* *}$ Engenheira Agrônoma, mestre e doutora em Zootecnia. Docente/Pesquisadora no Departamento de Zootecnia da Universidade Federal de Rondônia (UNIR), Campus de Presidente Médici (RO), Brasil.

*** Médico Veterinário, mestre e doutor em Zootecnia. Docente/Pesquisador do Departamento de Zootecnia da Universidade Federal de Rondônia (UNIR), Campus de Presidente Médici (RO), Brasil.

**** Zootecnista, mestre e doutor em Agronomia. Docente/Pesquisador do Departamento de Agronomia da Universidade Federal de Rondônia (UNIR), Campus de Rolim de Moura (RO), Brasil.

****** Engenheira Agrônoma, Mestre em Ciências Ambientais. Doutoranda no Programa de Pós-graduação em Agronomia - Sistemas de Produção. Universidade Estadual Paulista Júlio de Mesquita Filho (UNESP), Brasil.
} 
PALAVRAS-CHAVE: Bovinos de Corte; Confinamento; Pasto Suplementado; Sistemas Tecnificados.

\title{
METHANE EMISSION IN BREEDING AND FINISHING OF BULLS WITH DIFFERENT LEVELS OF TECHNOLOGY
}

\begin{abstract}
Production performance and methane production in two breeding and finishing systems in the state of Rondônia, Brazil, are evaluated. Study comprised totally randomized design, with two treatments, with 128 non-castrated heifers, mean initial weight $281.906 \pm 1.69 \mathrm{~kg}$. Production systems were classified by technology level employed, with supplementary pasture and finishing in confinement (SPC) as the highest technology-based production system, and breeding and finishing with supplementary pasture (SP), as average technology level. SP system had the greatest pasturing pressure on breeding, lowest availability of $\mathrm{DM}(\mathrm{t} / \mathrm{ha})$ and highest stocking rate. Breeding period within the most technical system was reduced to 61 days, with a $41.42 \%$ decrease in $\mathrm{CH}_{4}$ per kg of body weight. Finishing cycle was concluded in 94 days prior to the SPC system, with a decrease of $57.20 \% \mathrm{CH}_{4}$ emission per $\mathrm{kg}$ of body weight gain. Results show that the technology level applied to animal production affects performance. In $\mathrm{CH}_{4}$ evaluation of weight gain, it has the lowest impact on the environment by gas emission, decrease in the animal production cycle and faster financial returns.
\end{abstract}

KEY WORDS: Beef cattle; Confinement; Supplementary pasture; Technical systems.

\section{INTRODUÇÃO}

As questões ambientais têm sido muito pesquisadas no que tange à pecuária, principalmente a pecuária de corte, que tem recebido duras críticas a respeito de sua operacionalização, decorrente da produção de gás metano da fermentação entérica dos animais. $\mathrm{O}$ metano $\left(\mathrm{CH}_{4}\right)$ produzido em sistemas de produção de bovinos origina-se, principalmente, da fermentação entérica (85 a 90\%), sendo o restante produzido a partir dos dejetos desses animais (GONÇALVES; BARCELOS, 2014).

A bovinocultura de corte tem grande representatividade econômica no país. O Brasil possui o maior rebanho comercial de bovinos do mundo, com 215,2 milhões de animais e registro de abate de 29,67 milhões de cabeças no ano de 2016 
(IBGE, 2017). Na grande maioria dos Estados do país, em 2016, foi constatada redução no número de animais abatidos, diferentemente do que ocorreu no Estado de Rondônia, localizado na região Norte do Brasil, onde o total de animais abatidos no ano foi de 2,15 milhões de cabeças, acréscimo de 13,2\% em relação ao ano anterior. No entanto, a queda nacional no volume de animais abatidos não gerou, proporcionalmente, quedas nos rendimentos dos pecuaristas, uma vez que o preço médio da arroba bovina foi 5,15\% maior em 2016, média anual de $\mathrm{R} \$$ 152,90 (cento e cinquenta e dois reais e noventa centavos) por arroba, no comparativo 2016/2015. O cenário indicou abates de menor número de animais a rendimentos e preços melhores, demonstrando tendência de sistemas de produção mais eficientes (IBGE, 2017).

O sistema de exploração da pecuária bovina no Brasil, adotando como critério classificatório o nível de tecnologia empregado e o plano nutricional, pode ser classificado em três categorias, sendo estes: sistema de produção do tipo extensivo, semi-intensivo e intensivo, podendo englobar em uma única propriedade as fases de cria, recria e terminação ou atender frações destas fases, como a venda de bezerros ou bois magros para terminação em propriedades que atuam unicamente com o subsistema de terminação, ou ainda realizar a compra de bezerros ou bois para recria ou terminação (WILLERS, 2014; CEZAR, 2005). Entretanto, a predominância no país é do sistema de produção extensiva, de boi a pasto em áreas de pastagens cultivadas com forrageiras tropicais associadas à suplementação alimentar e animais predominantemente zebuínos, sendo a raça nelore a de maior ocorrência (VALADARES FILHO et al., 2006).

O Brasil é o país com maior potencial de expansão agropecuária do mundo, no entanto, vem sendo subutilizado, produzindo apenas entre 32 a $34 \%$ da sua capacidade, resultado da baixa produtividade das pastagens nacionais, com destaque para uso de reduzida tecnologia de produção, incluindo sobrepastoreio, ausência de fertilização de solo e sanidade animal (STRASSBURG et al., 2014). O país apresenta índices produtivos e econômicos pouco representativos de uma pecuária desenvolvida. Comparativamente, os Estados Unidos, com rebanho médio de 86 milhões de cabeças de bovinos, produzem cerca de 30\% mais carne/hectare/ano que o Brasil, por meio da adoção de sistemas de produção do tipo intensivo e semi-intensivo em grande escala (ANULPEC, 2015). 
A baixa produtividade da pecuária nacional não reflete apenas em índices financeiros, mas também influencia diretamente na geração de gases de efeito estufa, como o metano de fonte entérica, uma vez que a pastagem degradada ou de baixa produtividade favorece o baixo desempenho dos animais e, consequentemente, a maior produção de Gases de Efeito Estufa (GEE) por produto (MONTEIRO, 2009).

A terminação em confinamento tornou-se estratégica no planejamento pecuário por atrelar a liberação de áreas e minimizar os efeitos da seca no desempenho animal. De acordo com a ABIEC (2017) o número de animais terminados em confinamentos, entre os anos de 2010 a 2015, foi 5,05 milhões, o que representou $13 \%$ do volume de abate nacional. No ano de 2016, o volume caiu para 4,61 milhões de cabeças, $12,49 \%$ do abate total do Brasil, decorrente dos custos elevados com a aquisição de insumos agrícolas, como o milho.

$\mathrm{O}$ intuito do uso do sistema de produção em confinamento é o de produzir maior quantidade de carne ou de leite em menores áreas de pastagem (DIAS FILHO, 2014). Desta forma, espera-se, associado à adoção de novas tecnologias, reduzir os impactos ambientais, pela menor emissão de metano por quilo ganho de peso corporal.

O presente trabalho teve como objetivo avaliar o desempenho produtivo e a emissão de metano nas fases de recria e terminação de bovinos com o uso de diferentes níveis de tecnologia.

\section{MATERIAL E MÉTODOS}

\subsection{DESCRIÇÃO DO LOCAL DE ESTUDO E DELINEAMENTO EXPERIMENTAL}

O estudo foi desenvolvido em duas propriedades localizadas no Estado de Rondônia, denominadas de: propriedades com pasto suplementado e confinamento (PSC) e pasto suplementado (PS), no período de janeiro de 2016 a maio de 2017. $\mathrm{O}$ experimento foi realizado em delineamento inteiramente casualizado, composto por dois tratamentos, diferenciando-se pela tecnologia aplicada nas fases de recria e terminação, sendo o nível de tecnologia alta (NTA) constituído por pasto suplemen- 
tado na fase de recria e confinamento na terminação (PSC), e o nível de tecnologia média (NTM), constituído por pasto suplementado (PS), nas fases de recria e terminação, contendo 88 e 40 unidades experimentais, respectivamente. Os animais constituintes dos lotes em estudo foram predominantemente da raça Nelore ou mestiços de Nelore, machos e não castrados.

$\mathrm{Na}$ propriedade PSC, foram estudados 88 animais com peso e idade médios de 276,20 $\pm 1,60 \mathrm{~kg}$ e 18 meses, respectivamente, com oferta de suplemento proteico na quantidade média de $330 \mathrm{~g} /$ animal (Tabela 1) durante o período de 191 dias. A área experimental de recria foi de 34 hectares, formados com pasto Urochloa brizantha, cv. Marandu, com características bromatológicas conforme Tabela 2, provido de cocho coberto de quatro metros de comprimento e fonte de água oriunda de açude por represamento de águas da chuva.

Tabela 1. Níveis de garantia dos suplementos utilizados na suplementação nas fases de recria dos animais do lote PSC (pasto suplementado e confinamento) e na recria e terminação do lote PS (pasto suplementado), por quilo de produto

\begin{tabular}{lcc}
\hline \multirow{2}{*}{ Nutrientes } & \multicolumn{2}{c}{ Sistemas de Produção } \\
\cline { 2 - 3 } & PSC & PS \\
\hline Proteína bruta (g) & 300 & 100 \\
NNP - Equivalente Proteína (g) & 180 & 80 \\
Sódio (g) & 72 & 11 \\
Cálcio (g) & $20-30$ & $85-130$ \\
Fósforo (g) & 10 & 35 \\
Enxofre (g) & 10 & 10 \\
Magnésio (g) & 5 & 6 \\
Microminerais e aditivos & - & - \\
\hline
\end{tabular}

Níveis de garantia (mg/kg) para micro minerais e aditivos dos produtos fornecidos em PSC e PS, respectivamente: cobalto, 20 e 30; cobre, 250 e 700; flúor, 100 e 350; iodo, 20 e 25; manganês, 50 e 250; selênio, 5 e 5; selênio orgânico, 5 (presente somente em PS); zinco, 1.020 e 2.500; manano oligossacarídeos, 500; e virginiamicina, 500 presente em PSC; e Salinomicina, 600; e cromo orgânico, $8 \mathrm{mg}$ presente somente em $\mathrm{PS}^{1}$.

No sistema de produção PS foram utilizados 40 animais com peso e idade médios de 294,45 $\pm 3,33 \mathrm{~kg}$ e 18 meses, respectivamente. Neste experimento a área de pasto foi coberta uniformemente por Urochloa brizantha, cv. Marandu, e cerca 
de 30\% com Urochloa brizantha, cv. Xaraes. A propriedade adotou o sistema de pastejo intermitente, com período médio de pastejo de sete dias por piquete. A área dos piquetes foi de 32,67 hectares durante o período de 174 dias e de 18,15 hectares por período de 277 dias. Neste sistema de produção o tamanho do lote oscilou ao longo do estudo no sistema put and take, permanecendo em $6,21 \%$ do período em lote com total de 214 animais, 9,31\% com 234, 10,86\% com 82, 30,82\% com 76, $38,8 \%$ com 70 e 3,99\% em meio a lote 140 animais. Em 69,62\% do período estudado o lote foi composto de 70 a 76 animais, que compreendeu os meses de junho de 2016 a maio de 2017.

Em todas as áreas de pastagem da propriedade PS utilizaram-se cochos cobertos com quatro metros de comprimento. A dessedentação dos animais foi realizada via açude, por represamento de águas da chuva. Os animais receberam diariamente suplementação mineral energética, comercialmente conhecida como Sal Adensado, na quantidade de $112 \mathrm{~g} /$ animal na fase de recria e de 183,6 g/animal na fase de terminação (Tabela 1 ). As características médias bromatológicas do pasto são apresentadas na Tabela 2.

Tabela 2. Composição bromatológica da forragem na fase de recria no sistema PSC (pasto suplementado e confinamento) e nas fases de recria e terminação no sistema PS (pasto suplementado)

\begin{tabular}{lccc}
\hline & \multicolumn{2}{c}{ Recria } & Terminação \\
\cline { 2 - 4 } Item & PSC & PS & PS \\
\hline Matéria seca do pasto disponível (\%) & 51,86 & 56,55 & 50,47 \\
Matéria seca pastejo simulado (\%) & 35,72 & 28,88 & 35,28 \\
Proteína bruta (\%) & 9,36 & 9,82 & 7,45 \\
Matéria orgânica do pasto disponível (\%) & 95,44 & 92,11 & 93,23 \\
Matéria orgânica - pastejo simulado (\%) & 93,01 & 91,03 & 91,26 \\
Fibra em detergente ácido (\%) & 32,71 & 31,57 & 31,46 \\
Fibra em detergente neutro (\%) & 66,17 & 63,30 & 67,57 \\
\hline
\end{tabular}

$\mathrm{Na}$ fase de terminação, os animais do sistema PSC foram confinados em currais sem pavimentação com área de $1.050 \mathrm{~m}^{2}$, cochos em alvenaria sem cobertura, recebendo ração composta de silagem de milho e suplemento concentrado na rela- 
ção volumoso concentrado de 40:60, com base na matéria seca (MS), sendo a dieta formulada com 14,75\% de proteína bruta (PB) e 77,63\% de nutrientes digestíveis totais (NDT). Os animais permaneceram no confinamento por período de 105 dias.

\subsection{PRODUÇÃO DE METANO}

Para a estimativa da produção de $\mathrm{CH}_{4}$ foi calculado o consumo de matéria seca (CMS), conforme os autores Azevedo et al. (2016), que estabeleceram equações de predição do CMS para zebuínos em pastejo, recebendo suplementação - eq. (01), e em confinamentos - eq.(02), todos em condições tropicais:

CMS $(\mathrm{kg} / \mathrm{dia})=-1,912+0,900 \times$ CMSs $+0,094 \times P C^{0,75}+1,070 \times G M D-1,395$ $x G M D^{2}$

$$
\left(\mathrm{R}^{2}=0,600\right)
$$

Onde:

CMSs = consumo de matéria seca de suplemento em $\mathrm{kg} / \mathrm{dia} ; \mathrm{PC}^{0,75}$ - peso corporal metabólico, em kg; GMD - ganho médio diário de peso corporal, $\mathrm{em} \mathrm{kg} / \mathrm{dia}$.

CMS $(\mathrm{kg} / \mathrm{dia})=-1,303+0,0029 \times \mathrm{NC}-0,00005 \times N C^{2}+0,0843 \times P C^{0,75}+2,243 x$ $G M D-0,271 \times G M D^{2}$

Em que:

NC - nível de concentrado na dieta (\% da MS total da dieta); CMS - consumo de matéria seca.

O cálculo da energia metabolizável ingerida foi realizado pela equação 03 .

$$
E M I(M J / d i a)=(C M S \times 2,21) \times 4,18
$$

Em que:

EMI - Energia metabolizável ingerida, em MJ/dia.

Para a estimativa de gás metano $\left(\mathrm{CH}_{4}\right)$ utilizou-se da equação proposta por Ellis (2007), expressa na equação 04. 
$\mathrm{CH}_{4}(M J / d)=2,94+0,0585 \times E M I(M J / d)+1,44 \times F D A(\mathrm{~kg} / \mathrm{d})-4,16 \times$ Lignina $(\mathrm{kg} / \mathrm{d})$

Em que:

FDA - fibra em detergente ácido, em kg/dia.

A análise estatística dos dados para se proceder a comparação entre as médias dos diferentes níveis tecnológicos foi realizada através do teste T de Student, ao nível de significância de 5,0\%.

\section{RESULTADOS E DISCUSSÃO}

O peso inicial médio dos animais na entrada na fase de recria foi maior em OS em comparação ao peso dos animais do lote PSC, no qual os animais responderam melhor ao tratamento, com maior ganho de peso, redução no tempo de recria e ganho médio diário de peso corporal superior em relação a PS, com valores de 35,14; 24,20; e 77,80\%, respectivamente

$\mathrm{Na}$ fase de recria o consumo de matéria seca (CMS) total foi de 5,98 vs 5,63 $\mathrm{kg}$, houve maior oferta de forragem, 4,46 vs $1,11 \mathrm{~kg} . \mathrm{MS} / 100 \mathrm{~kg}$ PC, de suplemento, 0,33 vs $0,11 \mathrm{~kg} /$ dia e consumo de energia metabolizável, 13,21 vs 12,43 Mcal/dia, e a taxa de lotação foi menor e fixa, comparando os sistemas de produção PSC e PS, respectivamente (Tabela 3).

O consumo de proteína bruta $(\mathrm{PB})$ estimado na fase de recria foi em média de 627,80 g/dia em PSC e de 552,30 g/dia em PS, seguindo as exigências nutricionais de zebuínos puros e cruzados recomendadas por Rotta et al. (2016, p. 212), para animais de $300 \mathrm{~kg}$, com GMD de 0,50 kg/dia, o sistema PSC atendeu as exigências em 100\% para PB e o sistema PS atendeu em 94,73\% as exigências de PB. 
Tabela 3. Média das variáveis de desempenho produtivo na fase de recria nos sistemas de produção a pasto suplementado e confinamento (PSC) e apenas em pasto suplementado (PS)

\begin{tabular}{|c|c|c|c|}
\hline \multirow{2}{*}{ Variáveis } & \multicolumn{2}{|c|}{ Sistema de Produção } & \multirow[t]{2}{*}{$\mathrm{CV}(\%)^{2}$} \\
\hline & PSC & PS & \\
\hline Peso corporal inicial (kg) & 276,20 & 294,45 & -- \\
\hline Peso corporal final $(\mathrm{kg})^{1}$ & $404,17 \mathrm{a}$ & $372,38 \mathrm{~b}$ & 3,99 \\
\hline Consumo de matéria seca total $(\mathrm{kg})^{2}$ & $5,98 \mathrm{a}$ & $5,63 \mathrm{~b}$ & 1,54 \\
\hline Consumo de matéria seca de pasto $(\mathrm{kg})^{2}$ & $5,65 a$ & $5,51 \mathrm{~b}$ & -- \\
\hline Oferta de forragem (kg MS/100 kg PC) & 4,46 & 1,11 & -- \\
\hline Consumo de suplemento (kg/dia) & 0,33 & 0,11 & -- \\
\hline Consumo de energia metabolizável (Mcal/dia) $)^{2}$ & $13,21 \mathrm{a}$ & $12,43 b$ & 1,53 \\
\hline Ganho de peso $(\mathrm{kg})^{1}$ & $122,26 \mathrm{a}$ & $90,47 \mathrm{~b}$ & 14,02 \\
\hline Ganho médio diário $(\mathrm{g} / \mathrm{dia})^{1}$ & $0,64 \mathrm{a}$ & $0,36 \mathrm{~b}$ & 14,07 \\
\hline Tempo de recria (dias) & 191 & 252 & -- \\
\hline Taxa de Lotação (UA/ha) & 1,98 & 3,66 & -- \\
\hline Produção de metano recria (Mcal/dia) & $2,01 \mathrm{a}$ & $1,94 \mathrm{~b}$ & 0,99 \\
\hline Produção de metano recria (Mcal/kg ganho de PC) & $3,21 \mathrm{a}$ & $5,48 \mathrm{~b}$ & 14,75 \\
\hline
\end{tabular}

${ }^{1}$ Médias seguidas de letras diferentes na mesma linha diferem entre si pelo teste T de Student ao nível de significância de 5,0\%. ${ }^{2}$ Coeficiente de variação.

A reduzida oferta de forragem aumenta a pressão de pastejo, calculada em 0,117 e 0,359 kg de PC por kg de MS, para os sistemas PSC e PS, respectivamente, sendo 2,06 vezes maior para PS em relação a PSC. O sistema PS, apesar de apresentar oferta de forragem por taxa de crescimento de 2,8 kg.MS/dia em lotação intermitente quinzenal, apresentou maior taxa de lotação, 3,66 UA/ha, enquanto PSC apresentou 1,98 UA/ha. A disponibilidade de MST foi menor em PS, 4,59 vs 7,59 (t/ha) em PSC, submetendo os animais a maior dependência de suplementação para complementação nutricional e possível aumento da eficiência das proteínas microbianas.

A produção e a produtividade de carcaças são determinadas em grande parte pela taxa de lotação (MONTEIRO, 2009). A taxa de lotação na fase de recria foi maior no sistema PS em comparação com o de uso de pasto suplementado mais 
confinamento (Tabela 3) e quando confinados os animais do sistema PSC tiveram disponibilidade de área conforme proposto por Branco (2015), que recomenda no mínimo $9 \mathrm{~m}^{2} /$ animal (Tabela 4 ).

Um pasto mantido sob lotação contínua e eficientemente manejado, no qual os animais estejam continuamente sujeitos a dietas com folhas jovens faz com que a digestibilidade da forragem consumida seja mantida em patamar mais elevado em relação à lotação intermitente (REIS et al., 2012). Os autores Reis et al. (2012) sugerem, ainda, a utilização de suplementação estratégica, como mecanismo de reduzir o tempo de abate, a permanência do animal na propriedade e, consequentemente, diminuir o número de estações secas na vida do animal.

$\mathrm{O}$ fornecimento de proteinado de baixo consumo de $0,333 \mathrm{~kg}$ animal/dia no sistema PSC atende as recomendações de Porto et al. (2011), que indicam fornecimento de proteinados de baixo consumo na quantidade de $1 \mathrm{~g} / \mathrm{kg}$ de peso corporal, para animais em fase de recria. Já a quantidade ofertada no sistema PS, 0,111 $\mathrm{kg}$ animal/dia, foi abaixo do recomendado. O fornecimento de suplementação em quantidade reduzida torna a estratégia de produção ineficaz, não respondendo ao esperado.

O uso de suplementação a pasto tem como premissa básica aumentar o consumo de pasto, melhorar a degradação da parede celular e acelerar a passagem dos componentes indesejáveis da dieta, resultando no aumento no desempenho animal, decorrente não apenas do maior consumo de forragem, mas de mudanças na digestibilidade ou na eficiência de utilização dos nutrientes (SAMPAIO et al., 2009; PORTO et al., 2011), impactando diretamente a geração de $\mathrm{CH}_{4}$ da fermentação entérica, uma vez que quanto melhor a qualidade da pastagem e processo metabólico, menor a energia expelida na forma de gás.

A estimativa de produção de $\mathrm{CH}_{4}$ na recria foi de 2,01 vs 1,94 Mcal/dia, valor levemente superior em PSC em relação a PS (3,60\%), respectivamente, no entanto, quando avaliado o volume de $\mathrm{CH}_{4}$ por ganho de peso corporal, o sistema PSC emitiu comparativamente $41,42 \%$ menos $\mathrm{CH}_{4}, 3,21$ vs 5,48 Mcal/kg ganho de peso corporal (Tabela 3).

A variação da emissão de $\mathrm{CH}_{4}$ foi, no estudo de Cezimbra (2015), consequência do consumo de matéria seca (CMS), das mudanças estruturais do pasto e da 
taxa de acúmulo de forragem afetadas pelas condições climáticas.

A composição bromatológica da forragem e o consumo de MS influenciaram as estimativas da produção de metano entérico desenvolvidas por Monteiro (2009), onde quanto melhor a qualidade do alimento fornecido menores foram as emissões diárias de metano por animal.

Analisando a fase de terminação dos animais, verificou-se que o peso corporal final foi maior para os animais do lote PSC em relação ao de PS, 544,08 vs 504,72 $\mathrm{kg}$, assim como resultou em maior CMS total, 9,80 vs 7,67 kg e consumo de energia metabolizável, 21,66 vs 16,95 Mcal/dia (Tabela 4), resultando em ganho médio diário superior, que apresentou 94 dias a mais para terminação dos animais, utilizando pasto suplementado. O ganho de peso vivo médio diário dos animais é crescente à medida que o sistema de produção é intensificado (MONTEIRO, 2009).

Os animais terminados em confinamento, recebendo dieta balanceada a base de silagem de milho e concentrado na proporção de 40:60, obtiveram ganho médio diário de $1,39 \mathrm{~kg} / \mathrm{d}$ (Tabela 4), valor 2,3 vezes maior em relação a PS (0,60 kg/ dia).

As exigências nutricionais de PB para animais com média de peso de 400 kg, GMD de 1,50 kg/dia, é conforme Rotta et al. (2016, p. 212), de 1.163 g/dia, que é suprida no sistema PSC, da mesma forma que o sistema PS, que com GMD de 0,60 $\mathrm{kg} /$ dia para animais com peso médio de $400 \mathrm{~kg}$, ofereceu em média 753,90 g/dia de $\mathrm{PB}$, de uma exigência de 694,00 g/dia.

O rendimento de carcaça foi 55,7 vs $53,6 \%$, nos sistemas PSC e PS, respectivamente (Tabela 4). $\mathrm{O}$ rendimento de carcaça representa a capacidade dos animais de converter a oferta de alimento em produto final e está relacionado, dentre outros, com a raça animal e sistema de produção adotado. Estudos desenvolvidos por Macedo et al. (2001) e Scot Consultoria (2014) identificaram variação no rendimento de animais a pasto e confinamento, sendo média de $52 \%$ a pasto e de $54 \%$ para animais de confinamento. 
Tabela 4. Média das variáveis de desempenho produtivo na fase de terminação e rendimentos de carcaças dos sistemas PSC (pasto suplementado e confinamento) e PS (pasto suplementado)

Variáveis

Sistema de Produção

$\mathrm{CV}(\%)^{1}$

Peso corporal inicial $(\mathrm{kg})$

PSC

PS

Peso corporal final - abate $(\mathrm{kg})$

Consumo de matéria seca de pasto $(\mathrm{kg})$

397,9

386,0

$544,08 \mathrm{a}$

$504,72 \mathrm{~b}$

4,27

Consumo médio de suplemento $(\mathrm{kg})$

-- $\quad 7,49$

-- $\quad 0,184$

Consumo de matéria seca total $(\mathrm{kg})^{2}$

$9,80 \mathrm{a}$

$7,67 \mathrm{~b}$

4,80

Consumo de energia metabolizável (Mcal/d) ${ }^{2}$

$21,66 \mathrm{a}$

$16,95 \mathrm{~b}$

4,80

Consumo de suplemento $(\mathrm{kg} / \mathrm{d})$

- $\quad 0,184$

Ganho de peso (kg)

146,18

118,72

16,58

Ganho médio diário (kg/dia)

1,39

0,60

16,89

Rendimento de carcaça quente (\%)

$55,7 \mathrm{a}$

$53,6 \mathrm{~b}$

2,65

Tempo de terminação (d)

105

199

Taxa de lotação (UA/ha)

Disponibilidade de área no confinamento $\left(\mathrm{m}^{2} / \mathrm{animal}\right)$

- $\quad 3,77$

Produção de metano (Mcal/dia) ${ }^{2}$

11,93

Produção de metano (Mcal/kg ganho de peso corporal) ${ }^{2}$

$2,94 \mathrm{a}$

$2,50 \mathrm{~b}$

4,05

$2,16 \mathrm{~b}$

$5,05 \mathrm{a}$

16,25

${ }^{1} \mathrm{CV}=$ Coeficiente de variação. ${ }^{2}$ Médias seguidas de letras diferentes na mesma linha diferem entre si pelo teste T de Student ao nível de significância de 5,0\%.

A produção de $\mathrm{CH}_{4}$ foi de 2,16 vs 5,05 Mcal/kg ganho de peso corporal, em PSC em comparação a PS, respectivamente, representando 57,2\% menos $\mathrm{CH}_{4}$ emitido por quilo de peso corporal produzido no sistema PSC (Tabela 4).

As perdas energéticas por eructação de gases formados no processo digestivo das fibras consumidas também estão relacionadas à participação de volumosos nas dietas, que normalmente variam de 6 a 18\% (GONÇALVES; BARCELOS, 2014). À medida que se aumenta o teor de concentrado das dietas, ocorrem decréscimos na produção de $\mathrm{CH}_{4}$, uma vez que o maior teor energético eleva o desempenho animal e, dessa forma, reduz a produção de metano por quilo de produto formado seja carne, leite ou lã (CHIZZOTTI et al., 2011). Em dietas compostas por até $90 \%$ de concentrados reduz a emissão de $\mathrm{CH}_{4}$ para valores entre 2 a 3\% (JOHNSON; JOHNSON, 1995). 
Ações que melhorem a eficiência do sistema de produção reduzem, proporcionalmente, a emissão de metano, embora a produção absoluta de metano, em Mcal/dia, aumente com o acréscimo do uso de concentrado, 2,94 vs 2,50 Mcal/ dia entre PSC e PS (Tabela 4). Estudo de Cezimbra (2015) demonstrou proporção inversamente proporcional entre a emissão de $\mathrm{CH}_{4}$ por quilo de MS consumida em função do consumo diário de MS. Recebendo dieta contendo $60 \%$ de concentrado, os animais de PSC emitiram 32,71\% menos $\mathrm{CH}_{4}$ (Mcal/ganho de peso corporal) na fase de terminação em relação à fase de recria.

Quando avaliada a emissão de $\mathrm{CH}_{4}$ por $\mathrm{kg}$ de peso vivo ganho, o sistema PSC apresentou emissão de $41,42 \%$ e $57,2 \%$ menor nas fases de recria e terminação, respectivamente, em comparação ao sistema PS. A avaliação da geração de gás metano por unidade de carcaça produzida é considerada por diferentes autores, como Cardoso (2012) e Monteiro (2009), como o melhor parâmetro para identificar as oportunidades de mitigação de produção deste gás.

Mudanças no manejo e alimentação de animais bovinos podem repercutir em uma redução das emissões destes gases por unidade de produto produzida (CARDOSO, 2012). A redução das emissões de $\mathrm{CH}_{4}$ do rúmen pode ser alcançada através do manejo alimentar, aumento do desempenho produtivo dos animais e utilização de aditivos (RAMIREZ; POSADA OCHOA; NOGUERA, 2014).

O ciclo de produção de PSC foi 66\% menor em comparação a PS, o que representa área de pastagem liberada 260 dias antes, podendo ser destinada para recria ou terminação de novo lote de animais, aumentando a taxa de desfrute da fazenda, consequentemente, sem demanda de abertura de novas áreas para atividade.

$\mathrm{Na}$ análise econômica dos sistemas de produção, a taxa de retorno sobre o capital investido foi de $\mathrm{R} \$ 1,44$ reais e $\mathrm{R} \$ 1,50$ reais nos sistemas PSC e PS, respectivamente (Tabela 5).

A menor taxa de retorno do sistema PSC está relacionada aos altos custos de alimentação na recria, pelo maior valor comercial do suplemento adquirido, $\mathrm{R} \$ 2,06$ vs 1,60 por quilo, entre os sistemas PSC e PS, respectivamente, adicionado a maior quantidade ofertada, e na terminação aos custos da dieta balanceada do período de confinamento. Entretanto, constatou-se que no sistema PSC houve a redução de custo de $\mathrm{R} \$ 40,60$ reais por deixar de pagar 2,03 meses de aluguel na recria e de $\mathrm{R} \$$ 62,6 reais de pasto não pago na terminação (Tabela 5), considerando este custo 
não acrescido sobre a produção, a diferença da estimativa de resultado financeiro ou a receita pelo aluguel do pasto foi de $\mathrm{R} \$ 103,20$ reais por animal. O sistema PSC apresentou para abate animais com maior ganho de peso diário, menor tempo de produção, rendimento de carcaça e remuneração por arroba de carcaça.

Tabela 5. Análise de desempenho econômico dos sistemas PSC (pasto suplementado e confinamento) e PS (pasto suplementado)

\begin{tabular}{|c|c|c|}
\hline \multirow[b]{2}{*}{ Variável } & \multicolumn{2}{|c|}{ Sistemas de Produção } \\
\hline & PSC & PS \\
\hline Consumo de suplemento na recria $(\mathrm{kg})$ & 63,6 (191d) & $28,22(252 d)$ \\
\hline Consumo de suplemento na terminação (kg) & -.-- & $36,62(199 \mathrm{~d})$ \\
\hline Custo aquisição bezerro de corte $(\mathrm{R} \$ / \text { animal })^{1}$ & $1.000,00$ & $1.000,00$ \\
\hline Custo comercial do suplemento $(\mathrm{R} \$ / \mathrm{kg})^{2}$ & 2,06 & 1,60 \\
\hline Investimento com suplementação na recria ( $\mathrm{R} \$ /$ animal) & 131,02 & 45,15 \\
\hline Investimento com suplementação na terminação (R\$/animal) & -.-- & 58,59 \\
\hline Custo da dieta de confinamento ( $\$ \$ /$ animal $)^{3}$ & $682,50(105 d)$ & ---- \\
\hline Custo mão de obra pasto (R\$/animal) ${ }^{4}$ & 56,03 (191d) & $132,29(451 d)$ \\
\hline Custo mão de obra confinamento (mês) ${ }^{4}$ & 33,25 (105d) & $-\cdots--$ \\
\hline Diferença entre os sistemas PSC e PS na recria (meses) & 2,03 & -.-- \\
\hline Diferença entre os sistemas PSC e PS na terminação (meses) & 3,13 & $-\cdots-$ \\
\hline Custo com pasto recria (R\$ animal/mês) $)^{5}$ & 127,33 & 168 \\
\hline Custo com pasto terminação (R\$ animal/mês) & ---- & 132,66 \\
\hline Custo total no período $(\mathrm{R} \$)$ & $2.030,13$ & $1.536,69$ \\
\hline Peso médio de abate (kg) & 544,08 & 504,72 \\
\hline Rendimento médio de carcaça (\%) & 55,69 & 53,62 \\
\hline Peso de carcaça em arroba (@) & 20,20 & 18,04 \\
\hline Valor da arroba $(\mathrm{R} \$ / @)$ & 140 & 128 \\
\hline Receita por animal (R\$) & $2.828,00$ & $2.309,38$ \\
\hline Lucro $(\mathrm{R} \$ / \text { animal })^{6}$ & 797,87 & 772,69 \\
\hline Receita com pasto alugado $(\mathrm{R} \$)^{5}$ & $103,20(5,16 \mathrm{~m})$ & $-\cdots-$ \\
\hline Retorno sobre o capital investido ${ }^{7}$ & 1,44 & 1,50 \\
\hline
\end{tabular}

${ }^{1}$ Custo do bezerro de corte de acordo com pesquisa realizada pela Associação de Assistência Técnica e Extensão Rural do Estado de Rondônia (Emater-RO), no mês de janeiro de 2016 no Estado de Rondônia; ${ }^{2}$ Custo comercial do suplemento usado em PSC foi em média de R\$61,89/sc de $30 \mathrm{~kg}$ e de R\$48,00/sc de $30 \mathrm{~kg}$ usado em P.S.; ${ }^{3}$ custo da dieta de confinamento foi de $\mathrm{R} \$ 6,50 \mathrm{animal} / \mathrm{dia} ;{ }^{4}$ custo mensal médio da mão de obra no Estado, com encargos, considerando 1 homem para 500 animais a pasto foi de $\mathrm{R} \$ 4,40 /$ animal e de $8 \%$ do custo da dieta para a mão de obra em confinamentos; ${ }^{5}$ Valor de aluguel mensal do pasto $\mathrm{R} \$ 20,00 /$ animal. ${ }^{6}$ Lucro $(\mathrm{R} \$)=$ Receita por animal $(\mathrm{R} \$)$ - Custo total no período $(\mathrm{R} \$){ }^{7}$ Lucro $(\mathrm{R} \$) \div$ custo total no período ( $\mathrm{R} \$$ ). 
O valor de remuneração por arroba de boi gordo comercializada pelos proprietários das fazendas foi de R\$140,00 -1@ no sistema PSC e de R\$128,00-1@ no PS. A disparidade entre os valores arrecadados por arroba pode estar relacionada ao período de abate, onde o lote do sistema PSC foi abatido no mês de outubro de 2016 e de PS no mês de maio de 2017, e ao sistema de remuneração adotado pelas unidades frigoríficas, que remunera por carcaças de melhor acabamento de gordura. Comparativamente, o sistema PSC ofereceu animais mais jovens ao abate, qualidade de carne superior, em decorrência da precocidade dos animais abatidos, retorno do investimento mais rápido, sendo de 5,16 meses antes em PSC em comparação a PS. Todavia, o retorno sobre o capital investido foi maior em PS (Tabela 5).

\section{CONSIDERAÇÕES FINAIS}

A intensificação dos sistemas produtivos reflete diretamente no desempenho animal e nos impactos sobre o meio ambiente. Na avaliação de dois sistemas de produção classificados como intensivo (PSC) e semi-intensivo (PS) constatou-se que no sistema mais tecnificado o tempo de recria foi reduzido em 61 dias, liberou $41,42 \%$ menos $\mathrm{CH}_{4}$ por quilo de ganho corporal. Na fase de terminação a avaliação permitiu concluir que o ciclo de produção foi reduzido em 94 dias, com 57,2\% menos emissão de $\mathrm{CH}_{4}$ por quilo de ganho corporal.

$\mathrm{O}$ nível de tecnologia aplicada à produção animal influencia no volume de produto final gerado, o que, na avaliação de $\mathrm{CH}_{4}$ por ganho de produto produzido, representa menor impacto ao meio ambiente por emissão de gás e aumenta retorno financeiro.

Na avaliação econômica notou-se que são maiores os custos de produção à medida que há aumento nos investimentos nas fases de produção, constatando taxa de retorno menor no sistema PSC em relação a PS. Entretanto o tempo de retorno e o tempo de uso da terra foram menores para sistema PSC.

Desta forma, recomenda-se o sistema pasto mais suplemento proteico na recria, com confinamento na fase de terminação dos animais, quando se vislumbra a redução de metano por quilograma de peso corporal produzido. 


\section{REFERÊNCIAS}

ANUÁRIO BRASILEIRO DA PECUÁRIA DE CORTE 2015. Santa Cruz do Sul: Gazeta Santa Cruz, 2015.

ASSOCIAÇÃO BRASILEIRA DAS INDÚSTRIAS EXPORTADORAS DE CARNES. Perfil da Pecuária no Brasil. Relatório Anual 2017 [2018]. Disponível em: http://abiec. siteoficial.ws/images/upload/sumario-pt-010217.pdf. Acesso em: 21 fev. 2018.

AZEVEDO, J. A. G. et al. Regulação e predição de consumo de matéria seca. p. 1544. In: VALADARES FILHO, S. C et al. (ed.). Exigências nutricionais de zebuínos puros e cruzados - BR-Corte. 3. ed. Viçosa: UFV, DZO, 2016.

BRANCO, A. F. Manual de instalações para confinamento de bovinos. Maringá: IEPEC, 2015.

CARDOSO, A. S. Avaliação das emissões de gases de efeito estufa em diferentes cenários de intensificação do uso das pastagens no Brasil Central. Dissertação (Mestrado em Ciência do Solo) - Universidade Federal Rural do Rio de Janeiro, Seropédica, 2012.

CEZAR, I. M. et al. Sistemas de Produção de Gado de Corte no Brasil: Uma descrição com ênfase no regime alimentar e no abate. Embrapa Gado de Corte, Campo Grande, 2005. (Documentos, 151).

CEZIMBRA, I. M. Emissão de metano por bovinos sob níveis de oferta de forragem em pastagem nativa do Bioma Pampa. 2015. 96f. Tese (Doutorado em Zootecnia) - Universidade Federal do Rio Grande do Sul, Porto Alegre, 2015.

CHIZZOTTI, M. L.; LADEIRA, M. M.; MACHADO NETO, O. R.; LOPES, L. S. Eficiência da produção de bovinos e o impacto ambiental da atividade pecuária. In: VII SIMPÓSIO DE PECUÁRIA DE CORTE, 7., SIMPÓSIO INTERNACIONAL DE PECUÁRIA DE CORTE, 2., 2011. Anais [...]. Visconde do Rio Branco: Suprema, 2011, p. 37-60.

DIAS FILHO, M. B. Diagnóstico das pastagens no Brasil. Documentos, Embrapa Amazônia Oriental, Belém, 2014. 
ELLIS, J. L.; KEBREAB, K.; ODONGO, N. E.; MCBRIDE, B. W.; OKINE, E. K.; FRANCE, $\mathrm{J}$. Prediction of methane production from dairy and Beef cattle. Journal of Dairy Science, Savoy, v. 90, p. 3456-3466, 2007.

GONÇALVES, C. C. M.; BARCELOS, A. F. Fisiologia da Digestão dos Ruminantes. Cadernos Técnicos de Veterinária e Zootecnia, Belo Horizonte, n. 74, p. 25-43, 2014.

INSTITUTO BRASILEIRO DE GEOGRAFIA E ESTATÍSTICA. Indicadores IBGE: Estatística da Produção Pecuária - Março de 2017 [2017]. Disponível em: ftp://ftp. ibge.gov.br/Producao_Pecuaria/Fasciculo_Indicadores_IBGE/abate-leite-couroovos_201604caderno.pdf. Acesso em: 05 abr. 2017.

JOHNSON, K. A.; JOHNSON, D. E. Methane emissions from catle. Journal of animal science, v. 8, p. 2483-2492, 1995.

MACEDO, M. P. et al. Características de carcaça e composição corporal de touros jovens da raça Nelore terminados em diferentes sistemas. Revista Brasileira de Zootecnia, v. 30, n. 5, p. 1610-1620, 2001.

MONTEIRO, R. B. N. C. Desenvolvimento de um modelo para estimativas da produção de gases de efeito estufa em diferentes sistemas de produção de bovinos de corte. 2009. 75f. Dissertação (Mestrado em Agronomia) - Escola Superior de Agricultura "Luiz Queiroz", Universidade de São Paulo, Piracicaba, 2009.

PORTO, M. O. et al. Ofertas de suplementos múltiplos para tourinhos Nelore na fase de recria em pastagens durante o período da seca: desempenho produtivo e características nutricionais. Revista Brasileira de Zootecnia, v. 40, n. 11, p. 2548-2557, 2011.

RAMIREZ, J. F.; POSADA OCHOA, S.; NOGUERA, R. Metanogênese ruminal e estratégias para a sua mitigação. Revista CES Medicina Veterinária y Zooctenia (Online), v. 9, n. 2, p. 307-323, 2014.

REIS, R. A.; et al. Suplementação como estratégia de produção de carne de qualidade em pastagens tropicais. Revista Brasileira de Saúde e Produção Animal. v. 
13, n. 3, Salvador, 2012.

ROTTA, P. P. et al. Exigências de proteína para bovinos de corte. In: VALADARES FILHO, S. C. et al. (ed.). Exigências nutricionais de zebuínos puros e cruzados - BR-Corte. 3. ed. Viçosa: UFV, DZO, 2016.

SAMPAIO, C. B. et al. Rumen dynamics of neutral detergent fiber in cattle fed lowquality tropical forage and supplemented with nitrogenous compounds. Revista Brasileira de Zootecnia, v. 38, n. 3, p. 560-569, 2009.

SCOT CONSULTORIA. Rendimento de carcaça em frigoríficos do Brasil. Disponível em: https://www.scotconsultoria.com.br/noticias/artigos/37616/rendimento-decarcaca-em-frigorificos-do-brasil-htm. Acesso em: 15 set. 2017.

STRASSBURG, B. B. N. et al. When enough should be enough: Improving the use of current agricultural lands could meet production demands and spare natural habitats in Brazil. Global Environmental Change. 28, p. 84-97, 2014.

VALADARES FILHO, S. C. et al. Exigências Nutricionais de Zebuínos no Brasil I. Energia. p. 57-74. In: VALADARES FILHO, S.o de Campos; Pedro Veiga Rodrigues Paulino; Karla Alves Magalhães (ed). Exigências Nutricionais de Zebuínos e Tabelas de Composição de Alimentos. BR-Corte. Viçosa: UFV, DZO, 2006.

WILLERS, C. D. Avaliação dos impactos ambientais da pecuária de Corte semi-intensiva. 2014. 86p. Dissertação (Mestrado em Ciências Ambientais) - Universidade Estadual do Sudoeste da Bahia, Itapetinga, 2014.

Recebido em: $19 / 09 / 2017$

Aceito em: 24/05/2018 